\title{
Validation of a pre-coded food diary with energy expenditure, comparison of under-reporters $v$. acceptable reporters
}

\author{
I. T. L. Lillegaard* and L. F. Andersen \\ Department of Nutrition, University of Oslo, Box 1046 Blindern, N-0316 Oslo, Norway
}

(Received 1 November 2004 - Revised 10 June 2005 - Accepted 19 July 2005)

\begin{abstract}
The objective of the present study was to compare energy intake (EI) assessed from a pre-coded food diary (PFD) with energy expenditure (EE) measured by a validated position-and-movement monitor (ActiReg ${ }^{\circledR}$; PreMed AS, Oslo, Norway) in a group of Norwegian 9-year-olds. Moreover, we examined whether and how under-reporters (UR), identified with ActiReg ${ }^{\circledR}$, differed from acceptable reporters (AR) according to food intake and BMI. A total of fifty-one 9-year-olds completed PFD and ActiReg ${ }^{\circledR}$. The present study showed that on average EI was underestimated by $18 \%$ compared with EE measured by ActiReg ${ }^{\circledR}$. The $95 \%$ confidence limits of agreement in a Bland-Altman plot for EI and EE varied from $1.97 \mathrm{MJ}$ to $-4.23 \mathrm{MJ}$ (SD 2) among the girls and from $0.74 \mathrm{MJ}$ to $-5 \cdot 26 \mathrm{MJ}$ (SD 2) among the boys. The Pearson correlation coefficient between EI and EE was 0.28 (P=0.05) for males and females combined. Fifty-seven per cent of the participants were classified as AR, $39 \%$ as UR and $4 \%$ as over-reporters with the PFD. Under-reporting of energy remains a problem with the PFD method used in a group of 9-year-olds, especially among boys. However, UR and AR did not show a systematic misreporting related to macronutrients, unhealthy foods or BMI.
\end{abstract}

Children: Energy intake: Energy expenditure: Dietary survey: Under-reporting

When children are the target population in dietary studies, there are other methodological challenges than among adults since the ability to self-report food intake is limited among children, and young participants need help from parents or other caregivers to report what they have been eating (Livingstone \& Robson, 2000).

In 2000, a nationwide survey among 9-year-old Norwegians (UNGKOST-2000) was conducted to provide detailed information on their current dietary habits. A pre-coded food diary (PFD) was chosen as the assessment method. The PFD method gives the opportunity for a detailed dietary registration at the same time as eliminating or reducing the need for measuring and writing compared with other registration methods (Becker et al. 1998). However, the known tendency for recording methods to underestimate food intake remained a potential limitation for the study (Black et al. 1991; Livingstone \& Robson, 2000; Black \& Cole, 2001; Bandini et al. 2003; Livingstone \& Black, 2003).

A number of dietary studies have observed the tendency to underreport energy intake (EI) among adults (Black et al. 1991; Hill \& Davies, 2001) as well as children (Livingstone \& Robson, 2000; Livingstone \& Black, 2003). Moreover, studies among children and adolescents have observed increasing under-reporting with age (Bandini et al. 1997, 2003; Champagne et al. 1998). Underreporting in dietary studies may not be food- or nutrient-neutral. Several studies among adults have observed that fat intake, sweets and snacks are more likely than other foods to be under-reported (Pryer et al. 1997; Goris et al. 2000; Krebs-Smith et al. 2000). Few studies have been conducted among children and adolescents addressing these issues (Sjöberg et al. 2003).

The aim of the present study was to compare EI assessed from a PFD with energy expenditure (EE) measured by a validated position-and-movement monitor (ActiReg ${ }^{\circledR}$; PreMed AS, Oslo, Norway) in a group of Norwegian 9-year-olds, both at group level and for ranking of EI. Moreover, we examined whether and how under-reporters (UR) differed from acceptable reporters (AR) according to food intake and BMI.

\section{Subjects and methods}

Subjects

All students from the 4th grade (9-year-olds) in four schools ( $n$ 167) were invited to take part in the validation study. Seventy-three students agreed to participate. A total of twenty-two subjects were excluded, six because of missing PFD or illness for more than $2 \mathrm{~d}$ during the recording period and sixteen due to an ActiReg ${ }^{\circledR}$ measurement period of less than $4 \mathrm{~d}$. Data from fifty-one participants (31\%) were available for comparison between PFD and ActiReg ${ }^{\circledR}$.

The regional ethical committee approved the study, and informed consent was obtained from parents. 


\section{Design}

Data collection was carried out during March to May 2003. The 9-year-olds received an invitation letter at school. Children and parents who wanted to participate returned the informed consent. At least one parent of each child who wanted to participate attended an information meeting at the school, where project staff gave instructions on how to fill in the PFD and how to use the ActiReg ${ }^{\circledR}$. Researchers emphasized that the parents/participants should not change eating patterns during the food recording period or activity patterns during the ActiReg ${ }^{\circledR}$ measurement period.

The PFD recording period started the first Wednesday after the information meeting and lasted for four consecutive days. Participants started wearing the ActiReg ${ }^{\circledR}$ monitor the same day they started filling in the PFD.

Researchers telephoned all parents/participants on the second day of the recording period to encourage participation and answer any questions. Parents and participants could also call the project staff at any time with questions.

\section{Pre-coded food diary and photographic booklet}

The PFD using household measures and photographs for portion size estimation was newly developed for use among Norwegian children and adolescents (Øverby \& Andersen, 2002). The 18page PFD had lists of 277 food items (twenty-eight drinks, twenty-four dishes and 255 food items) grouped together according to the typical Norwegian meal pattern (Øverby et al. 2004). Each food group was supplemented with open-ended alternatives. The design of the PFD was similar to a cross-table with food listed on the left and time span across the top. Food amounts in the PFD were presented in household units (e.g. glasses, pieces or tablespoons) or as portions estimated from photographs. Along with the food diary, each participant received a photographic booklet that contained thirteen series of colour photographs, each with four different photographs ranging from small to large portion sizes (Lillegaard et al. 2005). Participants indicated an eating event by filling in how many units they had eaten of each food item in the correct time span.

The PFD was scanned using the Teleform program, version 6.0 (Datascan, Oslo, Norway). Daily intake of energy was computed using the food database and software system (KBS, version 4.7, 2004) developed at the Department of Nutrition, University of Oslo. The food database is based mainly on the official food composition table (Rimestad et al. 2000).

\section{ActiReg $^{\circledR}$}

The ActiReg ${ }^{\circledR}$ system (PreMed AS, Oslo, Norway) uses a combined second-to-second recording of body position and motion to calculate EE. The monitor has two pairs of position-andmotion sensors connected by cables to a battery-operated storage unit fixed to a waist belt. Each pair of sensors is attached by medical tape to the chest and the front of the right thigh respectively. The storage capacity of ActiReg ${ }^{\circledR}$ is sufficient for more than $30 \mathrm{~d}$ of continuous registration of normal activity. Collected data are transferred to a computer and processed by a dedicated program called ActiCalc ${ }^{\circledR}$. Further details about the ActiReg ${ }^{\circledR}$ monitor are published elsewhere (Hustvedt et al. 2004). The ActiReg ${ }^{\circledR}$ system has been validated against both the doubly labelled water (DLW) method and whole-body indirect calorimetry (IC) among young adults (Hustvedt et al. 2004). Both validation experiments demonstrated that there was no significant mean difference between EE measured with $\operatorname{ActiReg}^{\circledR}$ and EE measured with IC or the DLW method. The Bland-Altman plot for EE measured with IC and EE measured with ActiReg ${ }^{\circledR}$ (plot of $\mathrm{EE}_{\text {ActiReg }}-\mathrm{EE}_{\mathrm{IC}} v$. the mean of $\mathrm{EE}_{\text {ActiReg }}$ and $\mathrm{EE}_{\mathrm{IC}}$ ) showed a mean difference of $-8 \mathrm{~kJ} / \mathrm{h}$, and the $2 \mathrm{SD}$ limits of agreement were 152 and $-168 \mathrm{~kJ} / \mathrm{h}$ respectively (Hustvedt $e$ al. 2004). The Bland-Altman plot for EE measured with the DLW method and EE measured with ActiReg ${ }^{\circledR}$ (plot of $\mathrm{EE}_{\text {ActiReg }}-$ $\mathrm{EE}_{\mathrm{DLW}} v$. the mean of $\mathrm{EE}_{\mathrm{ActiReg}}$ and $\mathrm{EE}_{\mathrm{DLW}}$ ) showed a mean difference of $-0.41 \mathrm{MJ}$, and the $2 \mathrm{SD}$ limits of agreement were 3.10 and $-2 \cdot 30 \mathrm{MJ}$ respectively (Hustvedt et al. 2004). Moreover, the correlation coefficients between EE measured with ActiReg ${ }^{\circledR}$ and EE measured with IC and DLW were 0.86 and 0.70 respectively (BE Hustvedt, unpublished results).

\section{Body weight, height, BMI and BMR}

Body weight and height were measured by project staff. Weight was measured with a digital scale $( \pm 0.1 \mathrm{~kg})$ while the participant wore light clothing, trousers and a T-shirt/sweater. Height was measured to the nearest $0.5 \mathrm{~cm}$. BMI was calculated as body weight divided by the square of height $\left(\mathrm{kg} / \mathrm{m}^{2}\right)$. Estimate BMR were calculated from equations based on weight, age and sex (Nordic Council of Ministers, 1996). (The equations are based on Schofield et al. 1985; WHO/FAO/UNU, 1985; and modified data, Commission of the European Communities, 1992.)

\section{Statistical methods}

Sample size calculation for the ActiReg ${ }^{\circledR}$ study was based on an SD of EI of $2 \mathrm{MJ}$ and a significance level of 0.05 with $80 \%$ power (Cole, 1997). We needed twenty-six individuals to be sure to detect a mean difference of $1 \cdot 1 \mathrm{MJ}$ between EE measured with ActiReg $^{\circledR}$ and EI assessed with the PFD.

Data are presented as means and standard deviations. Visual agreement between the methods was analysed using the technique proposed by Bland and Altman (1986), using a plot of the difference between the two methods $v$. the average of the measurements. This type of plot shows the magnitude of disagreement, spot outliers and any trend. Pearson correlation coefficients were also calculated. Agreement on category level between ActiReg ${ }^{\circledR}$ and PFD was examined by classification of EI divided into quartiles.

The accuracy of reported intake was calculated by expressing the ratio EI:EE, for which a value of 1 would mean complete agreement between EI and EE. AR were defined as having EI:EE in the range of $0 \cdot 80-1 \cdot 20$, UR had a ratio less than $0 \cdot 80$, and over-reporters (OR) had a ratio larger than 1.20. These definitions are partly based on the $95 \%$ confidence limits of agreement between EI and EE measured by the DLW method, as proposed by Black (2000). Differences between UR and AR were analysed using the independent samples $t$ test. Average percentage difference in food intake between UR and AR was calculated as

$$
[(\mathrm{UR}-\mathrm{AR}) / \mathrm{AR}] \times 100 \text {. }
$$

Results were considered to be statistically significant at $P<0.05$. Data were analysed using SPSS for Windows release 11.0 (SPSS Inc., Chicago, IL, USA). 


\section{Results}

Physical characteristics of all participants are shown in Table 1. The difference between EI and EE was significantly larger among boys $(23 \%)$ than among girls $(14 \%)$, with an average difference of $18 \%$ (Table 1).

Bland-Altman plots showing the difference between EI from the PFD and EE from the ActiReg ${ }^{\circledR}$ method plotted against the mean of the two methods are given in Figs 1 and 2. The plots illustrate that both under-reporting and over-reporting of EI occurred. The $95 \%$ confidence limits of agreement varied from $1.97 \mathrm{MJ}$ to $-4.23 \mathrm{MJ}$ (SD 2) among the girls and from $0.74 \mathrm{MJ}$ to $-5.26 \mathrm{MJ}$ (SD 2) among the boys, which indicate wide discrepancies between the two methods for individual subjects. However, the plots did not indicate that differences tended to increase as absolute EI increased.

Pearson correlation coefficients between reported EI and EE were 0.28 ( $P$ 0.05) for the whole group. Separated by gender, the correlation was $-0.003(P \quad 0.99)$ for girls and $0.46(P \quad 0.02)$ for boys. If the two girls who over-reported their EI were excluded, the correlation coefficient for girls increased to 0.23 ( $P$ 0.28).

The proportion of participants appearing in the same quartile with both ActiReg ${ }^{\circledR}$ and PFD was $37 \%$. Seventy-five per cent were classified into correct or adjacent quartiles, and $10 \%$ were grossly misclassified.

When comparing BMI with EI:EE, we found a correlation of $r-0.22\left(\begin{array}{ll}P & 0 \cdot 13\end{array}\right)$.

Among the fifty-one participants, $57 \%$ (sixteen girls and thirteen boys) were classified as AR, $39 \%$ (nine girls and eleven boys) as UR and $4 \%$ (two girls) as OR. EE was not significantly different

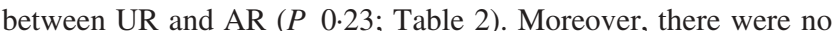
significant differences in BMI between UR and AR ( $P$ 0.77).

UR reported equal or lower intake of all food groups compared with AR, but the differences were not significant (Table 3 ). The percentage difference in intake of food groups between UR and AR varied from $6 \%$ to $31 \%$. UR reported significantly lower absolute intakes of all macronutrients compared with AR (Table 3). However, there were no significant differences in percentage of energy from macronutrients between UR and AR.

\section{Discussion}

The present study showed that EI was under-reported compared with EE measured with ActiReg ${ }^{\circledR}$. The under-reporting was

Table 1. Physical characteristics of the participants, BMR, energy expenditure (EE) measured with ActiReg ${ }^{\circledR}$ (PreMed AS, Oslo, Norway) and energy intake (EI) from the pre-coded food diary

(Mean values and standard deviations)

\begin{tabular}{|c|c|c|c|c|c|c|}
\hline & \multicolumn{2}{|c|}{ Total $(n 51)$} & \multicolumn{2}{|c|}{ Girls ( $n 27)$} & \multicolumn{2}{|c|}{ Boys (n 24) } \\
\hline & Mean & SD & Mean & SD & Mean & $S D$ \\
\hline Age (years) & $9 \cdot 4$ & 0.5 & $9 \cdot 4$ & 0.5 & $9 \cdot 3$ & 0.5 \\
\hline Height $(\mathrm{cm})$ & $142 \cdot 6$ & $5 \cdot 7$ & $143 \cdot 4$ & 5.5 & $141 \cdot 7$ & $5 \cdot 9$ \\
\hline Weight (kg) & 36.5 & 6.9 & $35 \cdot 6$ & 6.5 & $37 \cdot 4$ & $7 \cdot 3$ \\
\hline BMI $\left(\mathrm{kg} / \mathrm{m}^{2}\right)$ & $17 \cdot 8$ & 2.5 & $17 \cdot 2$ & $2 \cdot 1$ & $18 \cdot 5$ & $2 \cdot 7$ \\
\hline $\mathrm{BMR}^{*}(\mathrm{MJ} / \mathrm{d})$ & $5 \cdot 3$ & 0.6 & $5 \cdot 1$ & 0.5 & $5 \cdot 6$ & 0.6 \\
\hline$E E(M J / d)$ & 9.8 & 1.4 & $9 \cdot 2$ & 1.0 & $10 \cdot 6$ & 1.4 \\
\hline $\mathrm{El}(\mathrm{MJ} / \mathrm{d})$ & $8 \cdot 0$ & 1.4 & $7 \cdot 9$ & $1 \cdot 2$ & $8 \cdot 2$ & 1.6 \\
\hline $\mathrm{El}-\mathrm{EE}(\mathrm{MJ} / \mathrm{d})$ & -1.8 & 1.7 & $-1 \cdot 2$ & 1.6 & $-2 \cdot 4$ & 1.6 \\
\hline El:EE (MJ/d) & 0.83 & 0.16 & 0.88 & 0.17 & 0.78 & 0.13 \\
\hline
\end{tabular}

*BMR is estimated from equations (Nordic Council of Ministers, 1996).

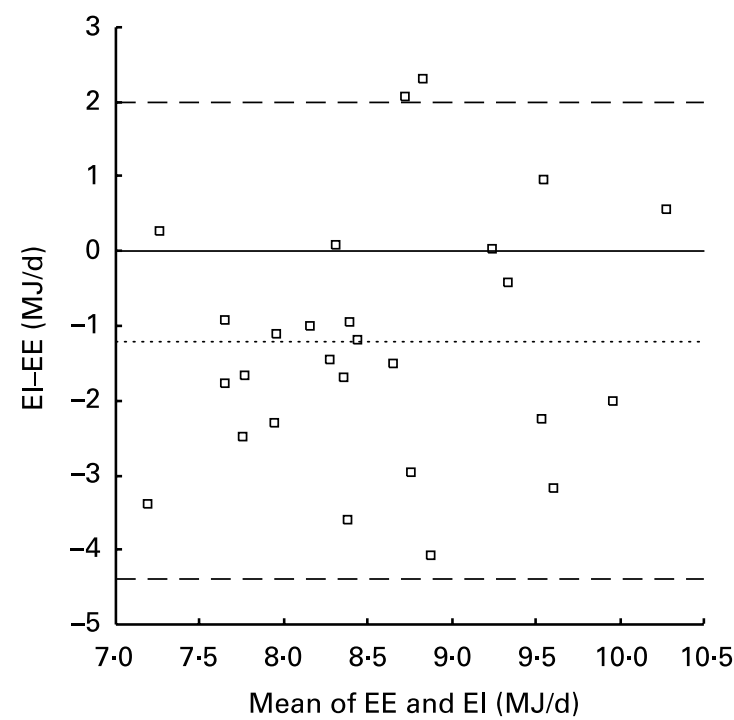

Fig. 1. The difference, among girls ( $n$ 27), between energy intake (EI) calculated from the pre-coded food diary and energy expenditure (EE) measured with the ActiReg ${ }^{\circledR}$ (PreMed AS, Oslo, Norway) plotted $v$. the mean of the two estimates. (.......), mean difference between the two methods; $(---)$, SD 2 limits of agreement.

larger among boys than girls, and there was substantial variability in the accuracy of the PFD at the individual level. However, there were no differences between participants classified as UR and AR in relation to percentage of energy from macronutrients.

The PFD method is less time-consuming for participants compared with traditional methods of obtaining food intake, like weighed food records, $24 \mathrm{~h}$ recall and dietary history. Furthermore, the PFD still captures much of the variability in food intake through extensive food lists and an open-ended approach. In focus group interviews for the present study, parents found the PFD easy to fill in. The daily time needed to complete the

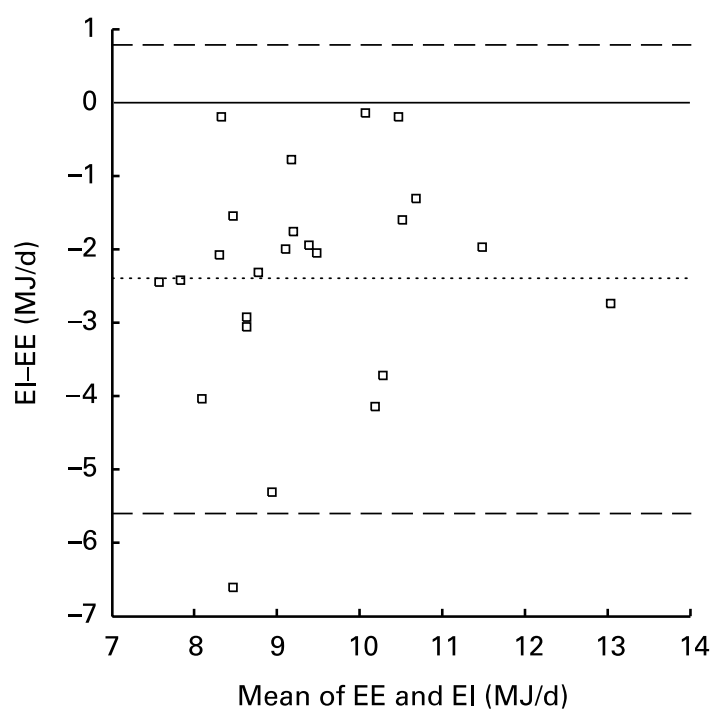

Fig. 2. The difference, among boys ( $n$ 24), between energy intake (EI) calculated from the pre-coded food diary and energy expenditure (EE) measured with the ActiReg ${ }^{\circledR}$ (PreMed AS, Oslo, Norway) plotted $v$. the mean of the two estimates. (.......), mean difference between the two methods; $(---)$, SD 2 limits of agreement. 
Table 2. Energy expenditure (EE) measured with ActiReg (PreMed AS, Oslo, Norway) and energy intake (EI) determined with the pre-coded food diary, and BMI, among under-reporters (UR) and acceptable reporters (AR) ${ }^{\star}$

(Mean values and standard deviations)

\begin{tabular}{lccccc}
\hline & \multicolumn{2}{c}{ UR $(n 20)$} & & \multicolumn{2}{c}{ AR $(n 29)$} \\
\cline { 2 - 3 } \cline { 6 - 6 } & Mean & SD & & Mean & SD \\
\hline EE $(\mathrm{MJ} / \mathrm{d})$ & 10.2 & 1.2 & & 9.7 & 1.4 \\
El $(\mathrm{MJ} / \mathrm{d})$ & 6.9 & 0.9 & & 8.7 & 1.2 \\
El $-\mathrm{EE}(\mathrm{MJ} / \mathrm{d})$ & -3.2 & 1.2 & & -1.0 & 0.9 \\
$\mathrm{El}: \mathrm{EE}(\mathrm{MJ} / \mathrm{d})$ & 0.69 & 0.09 & & 0.90 & 0.09 \\
$\mathrm{BMI}\left(\mathrm{kg} / \mathrm{m}^{2}\right)$ & 18.1 & 2.6 & & 17.8 & 2.5 \\
\hline
\end{tabular}

* UR were defined as having El:EE ratio of less than 0.80 , AR had a ratio in the range of $0 \cdot 80-1 \cdot 20$. Two subjects over-reported energy intake with the pre-coded food diary and are not included in the analysis.

PFD was about $10-15 \mathrm{~min}$, which was acceptable to both the children and their parents.

A few investigators have validated EI from record methods against DLW in this young age group. Livingstone et al. (1992) studied twenty-four children, aged 7-9 years, and found a mean $3 \%$ over-reporting in EI compared with EE. Champagne et al. (1998) studied 118 children, aged 9-10 years, and found under-reporting of EI varying from $18 \%$ to $23 \%$. And Bandini et al. (1997) studied eighty-seven 8-10year-old girls, and found that under-reporting varied from $3 \%$ to $16 \%$ according to age. The percentage of under-reporting in the present study $(18 \%)$ is within the range reported from these three studies. Similar studies to the present one have been conducted in two groups of Norwegian 13-year-olds (Andersen et al. 2005). Among these adolescents EI estimated from the PFD was found to be $24 \%$ and $34 \%$ lower than EE measured with ActiReg ${ }^{\circledR}$. The reasons for EI under-reporting are multifactorial. For 9-year-olds, reporting is likely to have been a shared task between parents and participants, with the parents responsible for actual reporting. However, parents depended on the children's reporting of eating events outside the home, and 9-year-olds may have attended after-school or other out-of-home activities during the recording period. In the present study, girls showed a smaller discrepancy between EE and EI than boys (Table 1). A possible explanation is that the girls, more so than the boys, wanted to show how well they could follow instructions and fill in the diary (Imsen, 1998).

We evaluated the extent to which EI from the PFD assigned the subjects into the same quartile of distribution as defined by EE from ActiReg ${ }^{\circledR}$. The PFD had a satisfactory ability to rank subjects in correct and adjacent quartiles (75\%); however $10 \%$ were grossly misclassified. When Pearson correlation coefficients were calculated, there was no linear association between the two methods among the girls, while the boys had a correlation coefficient of 0.46 .

The correlation coefficient is, however, widely viewed as inappropriate for assessing the level of agreement between two measurements. Therefore, the mean difference was calculated to obtain information on bias in the group estimate, and limits of agreement indicate the scatter of individual results. Applying the Bland-Altman plot to the energy data, we showed a mean difference with a large bias and a wide scatter of differences between self-reported EI and estimated EE. The wide scattering of the differences showed clearly that some subjects under- or over-reported their EI more than others. Under-reporting was a much larger problem than over-reporting, with $39 \%$ of the subjects identified as UR and $4 \%$ as OR.

Some studies (Champagne et al. 1998; Fisher et al. 2000) among children have observed a positive association between underestimation of EI and a tendency towards increasing weight

Table 3. Intakes of foods and food groups, absolute intakes of macronutrients and intakes of macronutrients as a percentage of energy from the pre-coded food diary among under-reporters (UR) and acceptable reporters $(A R)^{\star}$

(Mean values and standard deviations)

\begin{tabular}{|c|c|c|c|c|c|c|}
\hline & \multicolumn{2}{|c|}{ UR (n 20) } & \multicolumn{2}{|c|}{$\mathrm{AR}(n 29)$} & \multirow[b]{2}{*}{$P+$} & \multirow[b]{2}{*}{ \% Difference } \\
\hline & Mean & SD & Mean & SD & & \\
\hline Bread (g) & 115 & 41 & 135 & 51 & 0.15 & -15 \\
\hline Fruit and berries $(\mathrm{g})$ & 64 & 62 & 93 & 92 & 0.22 & -31 \\
\hline Fruit juice $(\mathrm{g})$ & 54 & 71 & 51 & 72 & 0.91 & 6 \\
\hline Vegetables (g) & 59 & 78 & 77 & 83 & 0.44 & -23 \\
\hline 5-a-day $(\mathrm{g}) \S$ & 176 & 113 & 222 & 135 & 0.22 & -21 \\
\hline Meat $(\mathrm{g})$ & 82 & 37 & 107 & 59 & 0.10 & -23 \\
\hline Milk (g) & 271 & 162 & 275 & 160 & 0.92 & -1 \\
\hline Chocolate and sweets (g) & 30 & 22 & 29 & 14 & 0.82 & 3 \\
\hline Soft drinks with sugar (g) & 242 & 77 & 327 & 205 & 0.09 & -26 \\
\hline Protein $(\mathrm{g})$ & 59 & 11 & 73 & 17 & 0.03 & -19 \\
\hline Fat $(g)$ & 56 & 12 & 75 & 14 & $<0.001$ & -25 \\
\hline Carbohydrate $(\mathrm{g})$ & 227 & 33 & 275 & 43 & $<0.001$ & -17 \\
\hline Sugar $(g)$ & 71 & 23 & 87 & 30 & 0.05 & -18 \\
\hline Protein (\% energy) & 14.5 & $2 \cdot 1$ & $14 \cdot 3$ & $2 \cdot 6$ & 0.71 & \\
\hline Fat (\% energy) & $29 \cdot 7$ & 4.6 & $31 \cdot 8$ & 3.6 & 0.08 & \\
\hline Carbohydrate (\% energy) & $55 \cdot 8$ & $5 \cdot 4$ & $54 \cdot 0$ & 4.9 & 0.23 & \\
\hline
\end{tabular}

*UR were defined as having El:EE ratio of less than 0.80 , AR had a ratio in the range of $0.80-1 \cdot 20$. Two subjects overreported energy intake with the pre-coded food diary and are not included in the analysis.

$\dagger P$ values from the $t$ test between independent samples.

$\ddagger \%$ Difference calculated as [(UR - AR)/AR] $\times 100$.

$\S 5$-a-day calculated from fruit and berries, fruit juice and vegetables. 
and body fatness. In the present study there was no significant association between BMI and the ratio EI:EE. Two other studies did not find an association between children's weight status and under-reporting (Johnson et al. 1996; Bandini et al. 1997).

Validation against EE identifies bias only in reporting of EI. This factor raises questions as to whether the diet is underreported as a whole, or whether there is selective under-reporting of different foods leading to further bias in the reporting of nutrient intake. Studies among adults suggest that UR report they consume less of all food groups, but that the degree of under-reporting varies between foods perceived as healthy or unhealthy (Bingham et al. 1995; Pryer et al. 1997; Johansson et al. 1998; Cook et al. 2000; Krebs-Smith et al. 2000; Lafay et al. 2000). Sjöberg et al. (2003) found no significant differences between UR, AR and OR in energy-adjusted intake of specific foods among adolescents (15-17 years old). To our knowledge, no previous studies have examined the association between EI and intake of food/food groups among children. In the present study UR did not under-report unhealthy foods like soft drinks with sugar, chocolate and sweets more than they under-reported other food groups like fruit and vegetables.

In some studies, UR among adults showed a lower intake of fat and simple carbohydrates compared with AR (Bingham et al. 1995; Johansson et al. 1998; Cook et al. 2000; Lafay et al. 2000). Sjöberg et al. (2003) found that adolescent UR had a lower fat intake, but did not differ from AR in relation to sucrose intake. In the present study, intakes of fat and sugar were not under-reported to a greater extent than other macronutrients among UR than AR.

The accuracy of EI estimated from dietary assessment methods may be validated against $E E$ when the subject is in energy balance. In the present study EE was measured with the new instrument, ActiReg $^{\circledR}$. Validation experiments against IC and DLW have demonstrated that ActiReg $^{\circledR}$ provides an estimate of EE at the group level that is comparable to results from heart rate and accelerometer recordings. Like these methods, ActiReg ${ }^{\circledR}$ shows considerable variation at the individual level, but the ranking is fairly good (Hustvedt et al. 2004). However, so far the ActiReg ${ }^{\circledR}$ has been validated only among young adults and not in children. Moreover, it has lately been shown that the WHO equation for estimation of resting energy expenditure, which was used in the ActiReg $^{\circledR}$ system for calculation of EE, systematically overestimated resting energy expenditure among children (Müller et al. 2004). This may have introduced an error resulting in an overestimation of the EE estimates from the ActiReg ${ }^{\circledR}$ system. The advantage of ActiReg ${ }^{\circledR}$ is that it enables more subjects to participate in a validation study, both because the technique is less expensive than the DLW technique and because the subjects do not have to collect urine samples or measure metabolic rate.

The participation rate in this study was $31 \%$; thus, study participants were a highly selective group. Validation studies often put a heavy workload on the participants. In the present study both the child and a parent had to find time for the child to wear the ActiReg ${ }^{\circledR}$ and register food intake for $4 \mathrm{~d}$; in addition they completed a $4 \mathrm{~d}$ weighed record the week after (data not shown). The parent's education level in this study was high overall. Comparing the EI in the validation study with the main survey UNGKOST-2000, the 9-year-old girls had 0.2 MJ higher EI in the validation study, while the boys had 0.4 MJ lower EI (Øverby \& Andersen, 2002). This indicates that EI in the validation study is at the same magnitude as in the main survey.
In summary, the PFD method underestimates the average EI compared with EE measured with ActiReg ${ }^{\circledR}$. Girls do not underestimate EI to the same extent as boys, with $14 \%$ and $23 \%$ underestimation respectively. There was substantial variability in the accuracy of EI of the PFD at the individual level. However, UR and AR did not show systematic misreporting related to macronutrients, unhealthy foods or BMI.

\section{Acknowledgements}

This study has partly been financed with the aid of EXTRA funds from the Norwegian Foundation for Health and Rehabilitation through the Norwegian Health Association.

\section{References}

Andersen LF, Pollestad ML, Jacobs DR Jr, Løvø A \& Hustvedt B-E (2005) Validation of a pre-coded food diary used among 13-yearolds: comparison of energy intake with energy expenditure. Public Health Nutr 8, 1317-1323.

Bandini LG, Cyr H, Must A \& Dietz WH (1997) Validity of reported energy intake in preadolescent girls. Am J Clin Nutr 65, Suppl., S1138-S1141.

Bandini LG, Must A, Cyr H, Anderson SE, Spadano JL \& Dietz WH (2003) Longitudinal changes in the accuracy of reported energy intake in girls 10-15y of age. Am J Clin Nutr 78, 480-484.

Becker W, Lennernäs M, Gustavsson I-B, Haraldsdóttir J, Nydahl M, Vessby B \& Ylterfors A (1998) Precoded food records compared with weighed food records for measuring dietary habits in a population of Swedish adults. Scand J Nutr 42, 145-149.

Bingham SA, Cassidy A, Cole TJ, et al. (1995) Validation of weighed records and other methods of dietary assessment using the $24 \mathrm{~h}$ urine nitrogen technique and other biological markers. Br J Nutr 73, 531-550.

Black AE (2000) The sensitivity and specificity of the Goldberg cut-off for EI:BMR for identifying diet reports of poor validity. Eur $J$ Clin Nutr 54, 395-404.

Black AE \& Cole TJ (2001) Biased over- or under-reporting is characteristic of individuals whether over time or by different assessment methods. J Am Diet Assoc 101, 70-80.

Black AE, Goldberg GR, Jebb SA, Livingstone MBE, Cole TJ \& Prentice AM (1991) Critical evaluation of energy intake data using fundamental principles of energy physiology. 2. Evaluating the results of published surveys. Eur J Clin Nutr 45, 583-599.

Bland JM \& Altman DG (1986) Statistical methods for assessing agreement between two methods of clinical measurement. Lancet 1, 307-310.

Champagne CM, Baker NB, Delany JP, Harsha DW \& Bray GA (1998) Assessment of energy intake underreporting by double labeled water and observations on reported nutrient intakes in children. J Am Diet Assoc 98, 426-433.

Cole TJ (1997) Sampling, study size, and power. In Design Concepts in Nutritional Epidemiology, pp. 64-86 [BM Margetts and M Nelson, editors]. Oxford: Oxford University Press.

Commission of the European Communities (1992) Reports of the Scientific Committee for Food. In Nutrient and Energy Intakes for the European Community. Thirty-first series of Food Science and Techniques, Luxembourg: Office for Official Publications of the European Communities.

Cook A, Pryer J \& Shetty P (2000) The problem of accuracy in dietary surveys. Analysis of the over 65 UK National Diet and Nutrition Survey. J Epidemiol Community Health 54, 611-616.

Fisher JO, Johnson RK, Lindquist C, Birch LL \& Goran MI (2000) Influence of body composition on the accuracy of reported energy intake in children. Obes Res 8, 597-603. 
Goris AHC, Westerterp-Plantenga MS \& Westerterp KR (2000) Undereating and underrecording of habitual food intake in obese men: selective underreporting of fat intake. Am J Clin Nutr 71, 130-134.

Hill RJ \& Davies PSW (2001) The validity of self-reported energy intake as determined using the doubly labelled water technique. Br J Nutr $\mathbf{8 5}$ $415-430$.

Hustvedt BE, Christophersen A, Johnsen LR, Tomten H, McNeill G, Haggarty P \& Løvø A (2004) Description and validation of the ActiReg ${ }^{\circledR}$ : a novel instrument to measure physical activity and energy expenditure. Br J Nutr 92, 1001-1008.

Imsen G (1998) Elevens verden: innføring i pedagogisk psykologi, Norway: Tano Aschehoug.

Johansson L, Solvoll K, Bjorneboe GE \& Drevon CA (1998) Under- and overreporting of energy intake related to weight status and lifestyle in a nationwide sample. Am J Clin Nutr 68, 266-274.

Johnson RK, Driscoll P \& Goran MI (1996) Comparison of multiple-pass 24-hour recall estimates of energy intake with total energy expenditure determined by the doubly labeled water method in young children. J Am Diet Assoc 96, 1140-1144.

Krebs-Smith SM, Graubard BI, Kahle LL, Subar AF, Cleveland LE \& Ballard-Barbash R (2000) Low energy reporters vs others: a comparison of reported food intakes. Eur J Clin Nutr 54, 281-287.

Lafay L, Mennen L, Basdevant A, Charles MA, Borys JM, Eschwege E \& Romon M (2000) Does energy intake underreporting involve all kinds of food or only specific food items? Results from the Fleurbaix Laventie Ville Sante (FLVS) study. Int J Obes Relat Metab Disord 24, 1500-1506.

Lillegaard ITL, Øverby NC \& Andersen LF (2005) Can children and adolescents use photographs of food to estimate portion sizes?. Eur J Clin Nutr 59, 611-617.

Livingstone MBE \& Black AE (2003) Markers of the validity of reported energy intake. J Nutr 133, Suppl., S895-S920.

Livingstone MBE \& Robson PJ (2000) Measurement of dietary intake in children. Proc Nutr Soc 59, 279-293.
Livingstone MBE, Prentice AM, Coward WA, Strain JJ, Black AE, Davies PS, Stewart CM, McKenna PG \& Whitehead RG (1992) Validation of estimates of energy intake by weighed dietary record and diet history in children and adolescents. Am J Clin Nutr 56, 29-35.

Müller MJ, Bosy-Westphal A, Klaus S, et al. (2004) World Health Organization equations have shortcomings for predicting resting energy expenditure in persons from a modern, affluent population: generation of a new reference standard from a retrospective analysis of a German database of resting energy expenditure. Am J Clin Nutr 80, 1379-1390.

Nordic Council of Ministers (1996) Nordiska näringsrekomendationer, p. 49. Copenhagen: Nordic Council of Ministers.

Øverby N \& Andersen LF (2002) Ungkost 2000. Landsomfattende kostholdsundersøkelse blant elever $i$ 4-og 8. klasse i Norge. Oslo: Sosial- og helsedepartementet.

Øverby NC, Lillegaard ITL, Johanson L \& Andersen LF (2004) High intake of added sugar among Norwegian children and adolescents. Public Health Nutr 7, 285-293.

Pryer JA, Vrijeheid M, Nichols R, Kiggins M \& Elliott P (1997) Who are the 'low energy reporters' in the dietary and nutritional survey of British adults? Int $J$ Epidemiol 26, 146-154.

Rimestad AH, Løken EB \& Nordbotten A (2000) The Norwegian food composition table and calculation system used at the Institute for Nutrition Research. Norwegian Epidemiology 107-110.

Schofield WN, Schofield C \& James WPT (1985) Basal metabolic rate: review and prediction. Hum Nutr Clin Nutr 39, Suppl. 1, 1-96.

Sjöberg A, Slinde F, Arvidsson D, Ellegard L, Gramatkovski E, Hallberg L \& Hulthen L (2003) Energy intake in Swedish adolescents: validation of diet history with doubly labelled water. Eur J Clin Nutr 57, 1643-1652.

World Health Organization/Food and Agriculture Organization/United Nations University (1985) Energy and Protein Requirements. Report of a Joint FAO/WHO/UNU Expert Consultation, Technical Report Series no. 724. Geneva: WHO. 